Regarding clozapine, our article states that all patients received classical neuroleptics (10-year follow-up concluded in 1993; by then, five patients were receiving sulpiride). Causes of death were not "lumped together" but, rather, aggregated by ICD-9 categories in accordance with general population statistics issued by the Department of Health; individual details on any of the above are available from us on request. Our data indicate that it is not increasing dose that is associated independently with reduced survival but, rather, increasing number of antipsychotics given concurrently; there were insufficient data to explore individual causes of death in relation to medication.

Altman, D. C. E Eland, J. M. (1998) Statistical notes: time to event (survival) data. British Medical journal, 317, 468-469.

J. L. Waddington, H. A. Youssef, A.

Kinsella Department of Clinical Pharmacology, Royal College of Surgeons in Ireland. St Stephen's Green, Dublin 2, Republic of Ireland

\section{Shotguns and blunderbusses: suicide in farmers}

Sir: I read with interest the Oxford study on the methods used by farmers to commit suicide over a 13-year period (Hawton et $a l, 1998)$. The authors demonstrated that the method of choice used by farmers in England and Wales was that of firearms, followed by hanging and carbon monoxide poisoning. The authors stated that "the ownership of firearms by farmers should be questioned". The paper, originating from the city of dreaming spires, demonstrates a lack of understanding of rural issues, and is disingenuous in its conclusions. Farmers unquestionably require firearms to control vermin, including rabbit, mink, crow and other infestations.

Working in a remote area of rural Scotland, I do not have access to detailed population statistics; however, a rule of thumb will suffice for this purpose. Assume that the population of England and Wales is approximately 50 million; that 1 in 75 of us die each year; then over 13 years (the period of the study), there will have been 8.7 million deaths. The authors imply that banning the ownership of firearms to farmers might prevent up to 285 deaths. This would have reduced the number of deaths in England and Wales by a factor of
$0.003 \%$. This does not appear to be a very impressive public health measure, even if it worked and if farmers did not choose to use alternative and rather more conventional methods such as analgesic or antidepressant overdosage. The rate of death due to firearms in this group has in any case been declining throughout this period (and not just since 1989, the date of firearms legislation, as the authors suggested).

Of course, if the authors were to sug gest that in addition to being prevented from owning firearms, that farmers were also prevented from owning ropes, balertwine and washing-lines (risk of hanging), and cars and agricultural vehicles and machinery (risk of carbon monoxide poisoning), then 613 deaths might be prevented, reducing the mortality in England and Wales by a whole factor of $0.007 \%$ ! Perhaps Hawton et al would prefer to see analgesics and antidepressants banned for townsfolk. By a similar reckoning, this would have a much greater impact in reducing deaths.

Hewron, K., Face, J., Simkin, S., et ol (1998) Methods used for suicide by farmers in England and Wales. The contribution of availability and its relevance to prevention. British fournal of Psychiatry, 173, 320-324.

R. A. Collacott Western Isles Hospital, Macaulay Road, Stornoway, isle of Lewis, Scotland HSI 2AF

Author'sreply: Dr Collacott's letter contains some surprising reasoning. First, to calculate the impact of suicide prevention in terms of the proportion of the overall number of deaths from all causes in the general population trivialises suicide prevention as a public health measure. Second, prevention of suicides in an individual group is surely worth pursuing, especially when that group has an elevated risk, as is the case with farmers (Charlton et al, 1993; Kelly \& Bunting, 1998). Third, reducing the availability of means for selfinflicted death is recognised as being an important component of suicide prevention. We were not suggesting that all farmers should be prevented from owning firearms, but that access to lethal weapons should be restricted for farmers known to be at risk of suicide. It is surely important to restrict access to firearms when a farmer (or indeed any other individual) is known to be at risk, such as during a severe depressive episode. One well-established fact is that unavailability of one method does not mean that a suicidal individual will automatically turn to another method. Also, some survivors of firearm suicide attempts report similar impulsivity in their actions to that often found in patients presenting with overdoses (De Moore et al, 1994).

The recent publication describing the results of our research team's work on suicide in farmers indicates several potential strategies for suicide prevention (Hawton et al, 1998). However, restricting access to means will always be one important strategy.

Chartion, J, Kelly, S., Dunmeli, K., ot of (1993) Suicide deaths in England and Wales: trends in factors associated with suicide deaths. Populotion Trends, 7 . $34-42$

Hawton, K., Simkin, S., Malmberg, A., et al (1998) Suicide and Stress in Formers. London: The Stationery Office.

Kelly, S. \& Bunting, J. (1998) Trends in suicide in England and Wales, 1982-96. Population Trends, 92, 29-41.

De Moore, G. M., Plew, J. D., Bray, K. M., et al (1994) Survivors of self-inflicted firearm injury. A liaison psychiatry perspective. Medical foumol of Australio. $160.421-425$.

K. Hawton University Department of Psychiatry, Warneford Hospital, Oxford OX3 7JX

\section{Satisfaction of carers at home}

Sir: Szmukler et al (1998) wondered whether the greater satisfaction of the carers of patients treated at home compared with hospital in the study of Marks et al (1994) might reflect the fact that the patients were being considered for admission at the time and had "enthusiastic experimental teams engaging in an exciting new form of care".

Two facts make the above explanations unlikely. First, the relatives' satisfaction with home care did not become significantly superior to satisfaction with standard hospital care until fully 11 months after patients had entered the study, well after admission had ceased to be an issue. Second, the relatives' significantly superior satisfaction with home rather than standard care continued when the patients were stable in the fourth year of the study, despite the experimental team by then having long been demoralised and without enthusiasm.

The relatives' superior satisfaction with home over standard care may more likely have reflected a preference for treatment 